\title{
Methods for Processing and Imaging Marsh Foraminifera
}

\section{Introduction}

This study is part of a larger U.S. Geological Survey (USGS) project to characterize the physical conditions of wetlands in southwestern Louisiana. Within these wetlands, groups of benthic foraminifera - shelled amoeboid protists living near or on the sea floor - can be used as agents to measure land subsidence, relative sea-level rise, and storm impact. In the Mississippi River Delta region, intertidal-marsh foraminiferal assemblages and biofacies were established in studies that pre-date the 1970s (Phleger, 1955; Warren, 1956; Lankford, 1959), with a very limited number of more recent studies. This fact sheet outlines this project's improved methods, handling, and modified preparations for the use of Scanning Electron Microscope (SEM) imaging of these foraminifera. The objective is to identify marsh foraminifera to the taxonomic species level by using improved processing methods and SEM imaging for morphological characterization in order to evaluate changes in distribution and frequency relative to other environmental variables. The majority of benthic marsh foraminifera consists of agglutinated forms, which can be more delicate than porcelaneous forms. Agglutinated tests (shells) are made of particles such as sand grains or silt and clay material, whereas porcelaneous tests consist of calcite.

Updated laboratory methods included (1) keeping the foraminifera moist to minimize post-collection breakdown of agglutinated forms, (2) applying of modern well-established taxonomy, and (3) using a small size fraction (> 45 micrometer $(\mu \mathrm{m}))$ to collect a larger proportion of foraminiferal specimens, including small adults and juveniles.

Short sediment cores (up to 0.6 meters (m)) were collected within the wetlands and transported to the laboratory at the USGS St. Petersburg Coastal and Marine Science Center. A protocol was established to image the cores using X-ray and the cores were then sectioned at 2-centimeters $(\mathrm{cm})$ intervals downcore through extrusion. Each $2-\mathrm{cm}$ interval was separately homogenized. From these intervals, 60 cubic centimeters $\left(\mathrm{cm}^{3}\right)$ volume subsamples were split into aliquots for analysis of environmental variables of grain size, organic carbon, isotope analysis of ${ }^{210} \mathrm{~Pb}$ and ${ }^{137} \mathrm{Cs}$, diatoms, dry-weight content, foraminifera, and replicates. This project focuses on the foraminiferal analysis. For the foraminiferal aliquot, a syringe with a cut-off tip was used to obtain a constant volume of $10 \mathrm{~cm}^{3}$ (fig. 1).

Improved sampling practices take into account the fact that benthic foraminifers live throughout the upper $10 \mathrm{~cm}$ of sediments (Ozarko and others, 1997). This is in contrast to older studies, which used samples taken from the upper $1 \mathrm{~cm}$ of sediment and, hence, missed species that live more than $1 \mathrm{~cm}$ below the marsh surface. Interval samples were treated with a 1:1 isopropyl-alcohol and water mixture and refrigerated until further analysis to prevent further deterioration by bacteria. Foraminiferal samples were collected and prepared using the protocols of Scott and Medioli (1978), de Rijk (1995), and Dreher (2006). Agglutinated foraminiferal recovery has been enhanced by use of wet methods throughout sample handling, including use of a settling-type splitter modified from a design of Scott and Hermelin (1993). All samples were handled wet throughout their preparation and census. In contrast, older studies typically dried samples at some point in their preparation and (or) microscopic examination.

Taxonomic improvements used in a recent USGS study of southwestern Louisiana marshes include updated morphology of juvenile forms, a more refined and stabilized taxonomy of adult forms, and addition of recently described taxa (for example, Polysaccammina ipohalina) to the list of species found in Mississippi Delta marshes (Scott and others, 1991; Dreher, 2006).

In addition to refined taxonomy, other improvements included greater fossil recovery by sieving to a smaller size
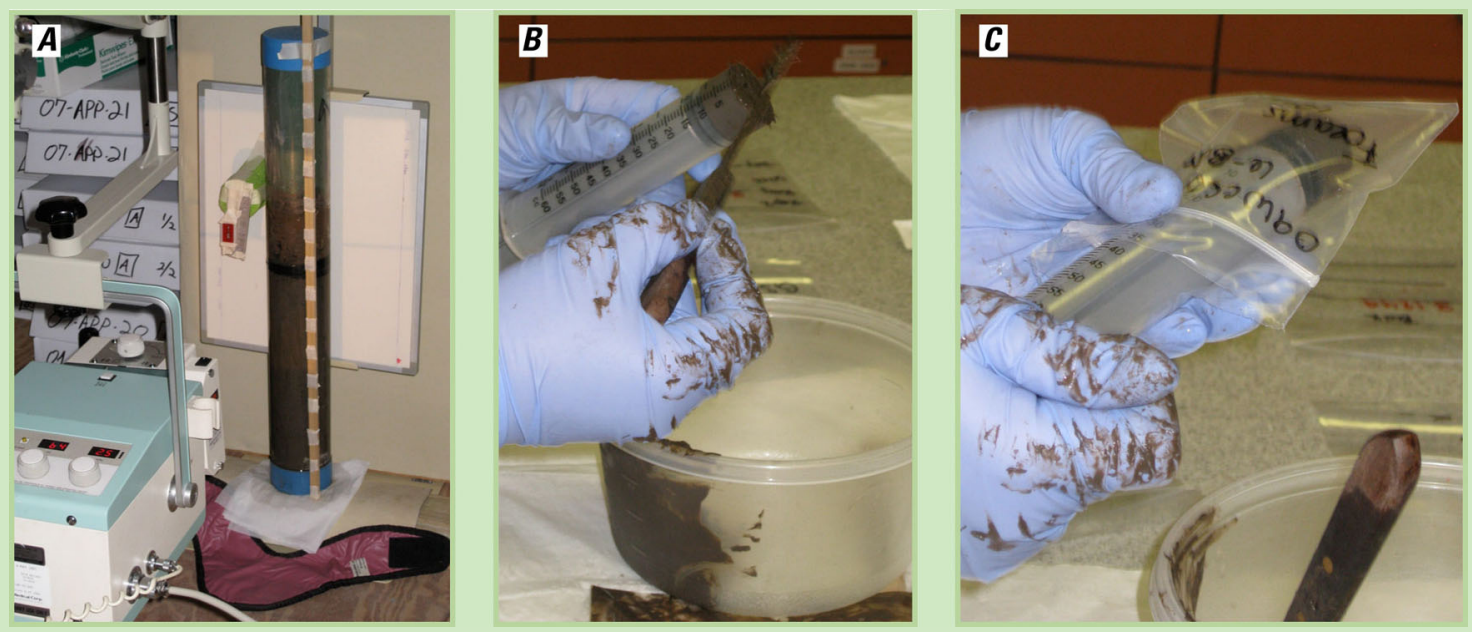

Figure 1. Laboratory preparations for subsampling marsh cores included $(A)$ imaging of the cores by $X$-ray, $(B)$ homogenizing extruded 2-cm-thick intervals and measuring known volume of subsamples from the intervals, and $(C)$ collecting $10 \mathrm{~cm}^{3}$ for a foraminifera subsample. 
fraction than used in previous studies. Sieving in previous works used a $>63-\mu \mathrm{m}$ fraction, which recovers medium to large adult foraminiferal specimens (de Rijk, 1995; Ozarko and others, 1997; Culver and Horton, 2005). Several recent studies conducted in marsh environments have incorporated the smaller sieve size of $45 \mu \mathrm{m}$, which has increased the recovery of small adult taxa, juveniles, and arcellaceans (freshwater foraminifera) (Scott and Medioli, 1978; Scott and others, 1991; Brunner, 2003; Dreher, 2006).

All foraminifera were classified and counted by placing the split sample into a gridded petri dish with water and observing the sample using a zoom stereo-microscope with magnification up to $100 \times$ (fig. 2). Examples of most species were photographed through the light microscope at the St. Petersburg Coastal and Marine Science Center (fig. 3A). All foraminiferal specimens were identified to species and counted until approximately 300 specimens were tabulated, to assure statistical significance based on sampling error (Patterson and Fishbein, 1989). Specimens were identified based on original descriptions augmented by revisions and well-illustrated publications, including those of Phleger (1955), Lankford (1959), Loeblich and Tappan (1987), Scott and others (1991), and numerous other publications. The census data for this project will calculate relative species frequencies and distributions and use statistical analysis to determine the correlation between the foraminferal species and the environmental variables (for example, grain size, salinity, or elevation). These environmental factors may influence the presence and abundance of species.

\section{Scanning Electron Microscopy Methods}

After foraminiferal specimens were identified, some were selected for evaluation using SEM to identify morphological features and to better resolve smaller specimens. These specimens were picked and stored in a small petri dish treated with a 1:1 water and isopropyl alcohol mixture and refrigerated until all desired specimens were obtained (fig. $3 B$ ). Under the light microscope, the small petri dish and a gridded cardboard slide were placed side by side. A water-dampened hairline paintbrush was used to transfer species from the petri dish to the cardboard slide (fig. 4A). The foraminiferal species were sorted into numbered squares on the slide. A SEM aluminum stub was prepared with double-sided sticky tape and placed next to the cardboard slide under the light microscope. The slide was able to absorb some of the moisture from the wet foraminifera. The slightly air-dried foraminifera were transferred to the stub using the hairline paintbrush dampened with a mixture of water and clear glue (fig. 4B). The foraminifera were placed on the stub in a radial-star pattern, and the location of each species from the slide and its location on the stub were noted for reference purposes. The stub was then covered to ensure that the foraminifera were not disturbed and to reduce accumulation of dust particles. The covered stub was allowed to air dry for several days. The prepared stub was then transferred to the SEM lab at the University of South Florida (USF) St. Petersburg campus, where it was placed in a gold-palladium (AuPd) sputter coater. The prepped stub was coated with AuPd for approximately 4 minutes. Coat time was increased depending on the porosity of the specimens. The sputter coating was repeated if electron charging occurred in the SEM. Length of repeat coating time

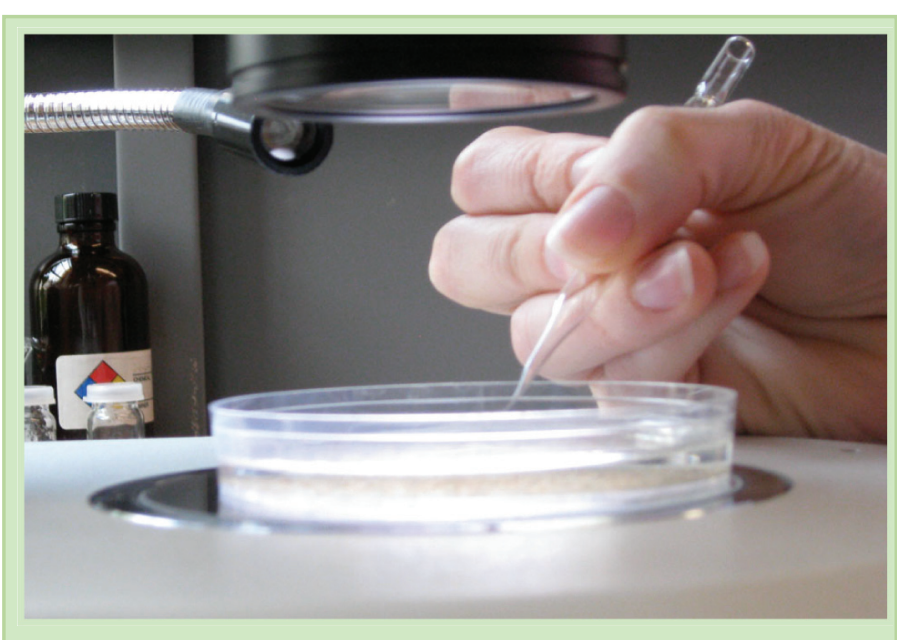

Figure 2. Foraminifera remained wet while census took place under a zoom stereo-microscope.


Figure 3. $(A)$ Foraminifera were photographed under a zoom stereomicroscope with a scope camera. $(B)$ Then the specimens were picked and placed into a small petri dish with a 1:1 isopropyl-alcohol and water mixture and refrigerated.

was dependent on the amount of charging. After coating, the stub was placed in a storage box within a dehydrating chamber with desiccant material to absorb air moisture to preserve the sample until SEM images were acquired. The sample was then imaged in the SEM, using the referenced notes of species location on the stub and light microscope photos to map areas of interest on the test. SEM images of a whole test should have a good depth of field, and for high-resolution images $(>40,000 \times)$ care was taken to align and remove or reduce any stigmatism that could blur the image. SEM secondary electron (SE) images are generated by primary beam electrons that excite and scattered secondary electrons from the sample surface and shallow subsurface. The secondary electron signals are collected in the form of photoelectrons to produce a surface image. 



Figure 4. $(A)$ Foraminifera were picked with a dampened hairline paintbrush from the small petri dish and placed on a gridded cardboard slide. Next, $(B)$ foraminifera were transferred from gridded cardboard slide with a dampened hairline paintbrush to a SEM aluminum stub prepared with double-sided sticky tape. Each specimen was brushed with the glue mixture to secure it to the stub.

\section{Agglutinated Foraminifera Structure}

Benefits of using SEM to image foraminiferal species, in addition to using a light microscope, include (1) identifying variations of morphology between foraminiferal species and (2) obtaining higher resolution of the detail of individual foraminiferal species. Detail of these microfossils is key in determining and identifying the taxonomy to the species level. Most of the agglutinated microfossils can be identified visually under a high-power $(70-100 \times)$ light microscope (fig. 5). However, some specimens, especially juveniles, can be quite similar, and a higher resolution and magnification are needed to observe the features that separate and correctly identify to the species level. The visual information provided by the SEM images can enable identifications to the species level with a higher degree of confidence. Variations in morphology in some microfossils have prompted their redescription and reclassification at the genus or species levels. These morphological differences can vary slightly from location to location around the world. Therefore, having SEM images of these species in question will help the researcher determine the best fit for classification to species

level. Obtaining SEM images of the microfossils provides typelocal images for the benthic marsh foraminifera in southwestern Louisiana.

Marsh foraminifera imaged by the SEM (figs. 6 - 8) for the USGS project represent surface samples from marsh cores collected along a transect from southwestern Louisiana. The transect represents gradational differences in salinity and elevation from near shore to interior marsh.

Information on agglutinated, marsh, and intertidal foraminiferal species in southwestern Louisiana and worldwide is primarily based on historic records or on original type-locality descriptions. A limited number of recent studies contain detailed SEM images of a few of these microfossils (Phleger, 1955; Lankford, 1959; Loeblich and Tappan, 1987; Scott and others, 1991). Agglutinated structures of these foraminifera are rarely seen in detail in these studies. By examining the structural detail, insight on foraminiferal relationships with elevation, salinity, total carbon, and grain size can be determined. It has been well documented that certain species of foraminifera can be proxies for investigating sea-level and marsh-elevation changes (Scott and Medioli, 1978; de Rijk, 1995; and others). However, few studies have been able to identify specific species of agglutinated foraminifera as long-term proxies for investigating wetland landscape change, stability, and persistence. In the USGS study, surface and downcore microfossil distributions, frequencies, and biofacies will be correlated with sedimentological and stratigraphic parameters to identify changes in the environmental conditions. These changes can include storm impact, subsidence, sea-level rise, and flooding. Depositional layers leave 'fingerprints' of ecological changes within the sedimentary record. The goal is to identify marsh and intertidal foraminifera to the taxonomic species level, as well as changes in distribution and frequency relative to other environmental variables. Statistical analysis of these data will provide species composition, abundance, biofacies, and statistical relationships with collected environmental data.


Trochamminita irregularis Cushman and Brönnimann, 1957 100x

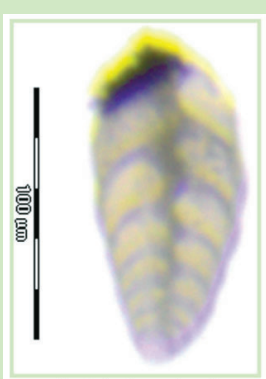

Textularia earlandi Parker, 1952 100x
Figure 5.

Light-microscope images of agglutinated foraminifera were taken before being placed on a SEM aluminum stub. These three species are represented in the SEM images in figures 6,7 , and 8 . All three are common in the marsh, ranging from interior to shallow sub-tidal areas.

Note: Readers should refer to Loeblich and Tappan (1987) for full taxonomic descriptions and references for all specimen images. 




right in image $C$ using split magnification. Image $D$ shows greater detail of the agglutinated fine sediments, most likely micas and clays, cemented together for a relatively smooth, flat surface. The larger, rounder grains are most likely cemented sand grains that give the image texture.

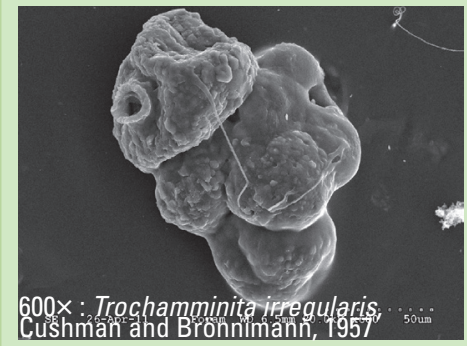

Figure 7. The above SEM SE image views the whole test of a Trochamminita irregularis. This agglutinated benthic foraminiferal species is distinctive due to its irregularly shaped chambers, after the initial round coil. Its aperture is distinct with one or more small round openings with a raised lip border in the last chamber wall.

\section{References}

Brunner, C.A., 2003, Foraminifer and arcellacean assemblages of Mississippi marshes: Geological Society of America Abstracts and Programs, v. 35, no. 6, p. 491.

Culver, S.J., Horton, B.P., 2005, Infaunal marsh foraminifera from the Outer Banks, North Carolina: Journal of Foraminiferal Research, v. 35, no. 2, p. 148-170.

de Rijk, S., 1995, Salinity control on the distribution of salt marsh foraminifera (Great Marshes, Massachusetts): Journal of Foraminiferal Research, v. 25, p. 156-166.

Dreher, C.A., 2006, Modern foraminiferal bio-facies within a transgressive saline influenced deltaic headland, South-Central Louisiana: Masters Thesis, University of New Orleans, 136 p., available at: http://louisdl.louislibraries.org/u?/NOD,443.

Lankford, R.R., 1959, Distribution and ecology of foraminifera from east Mississippi Delta margin: Bulletin of the American Association of Petroleum Geologists, v. 43, no. 9, p. 2068-2099.

Loeblich, A.R., and Tappan, H., 1987, Foraminiferal genera and their classification: Van Nostrand Reinhold Company, New York, 2 vols., $970 \mathrm{p}$.

Ozarko, D., Patterson, R.T., and Williams, J.F.L., 1997, Marsh foraminifera from Nanaimo, British Columbia (Canada): Implications of infaunal habitat and taphonomic biasing: Journal of Forminiferal Research, v. 27, no. 1, p. 51-68.

Patterson, R.T., and Fishbein, E., 1989, Re-examination of the statistical methods used to determine the number of point counts needed for micropaleontological quantitative research: Journal of Paleontology, v. 63, no. 2, p. 245-248.

Phleger, F.B, 1955, Ecology of foraminifera in southeastern Missisippi Delta area: Bulletin of the American Association of Petroleum Geologists, v. 39, p. 712-752.

Scott, D.B., and Hermelin, J.O.R., 1993, A device for precision splitting of micropaleontological samples in liquid suspension: Journal of Paleontology, v. 67, no. 1, p. 151-154.

Scott, D.B., and Medioli, F.S., 1978, Vertical zonations of marsh foraminifera as accurate indicators of former sea levels: Nature, $v$. 272, p. $538-541$.

Scott, D.B., Suter, J., and Kosters, L., 1991, Marsh foraminifera and arcellaceans of the lower Mississippi Delta: Controls on spatial distributions: Micropaleontology, v. 37, no. 4, p. 373-392.

Warren, A.D., 1956, Ecology of foraminifera of the BurasScofield Bayou region, southeastern Louisiana: Transactions of the Gulf Coast Association of Geological Societies, v. 6, p. 131-151.

\section{Contact Information}

Chandra A. Dreher cdreher@usgs.gov

USGS St. Petersburg Coastal and Marine Science Center 6004 th Street South

James G. Flocks St. Petersburg, FL 33701

jflocks@usgs.gov_http://coastal.er.usgs.gov/LA-subsidence/ We thank Meghan Maraia (Eckerd College) for assisting with lab subsampling of marsh cores and Tony Greco for assistance in SEM imagery. 